\title{
What Shall We Do with Psychological Processes?
}

\author{
Joseph K. Torgesen, PhD
}

The idea that learning disabilities are the result of deficiencies in one or more of the basic psychological processes required for learning is a core concept that needs to be maintained. However, problems in the application of traditional process-oriented approaches to diagnosis and treatment of learning disabilities suggest a need to alter the manner in which these basic processes are conceptualized and measured. Evidence from research in cognitive development indicates the need to change from child-centered process assessment to measurement of processes required for the performance of specific academic tasks in specific settings. This report suggests that such a change not only will encourage the search for the processing deficiencies underlying different kinds of learning disabilities but also will make the assessment of processes more relevant to education.

$\mathbf{0}$ ne of the most important controversies in the field of learning disabilities concerns the appropriateness of describing learning disabled children in terms of the deficient psychological processes underlying their learning problems. Although the new federal regulations (Federal Register, Dec. 29, 1977) that describe procedures for identifying learning disabled children contain a definition of learning disabilities in processing terms, there is no processing language in the operational procedures for diagnosing a learning disability. As Senf (1978) has pointed out, the definition indicates that learning disabilities arise from a deficiency in basic cognitive processes, which in turn leads to academic failure, but the actual procedures for identifying a learning disabled child simply cite a discrepancy between expected and attained achievement. In addition to these ambiguities in the federal regulation, traditional approaches, which attempt to describe and treat deficient learning processes, have been severely criticized on both pragmatic and conceptual grounds (Mann 1971, Smead 1977).

The new federal regulations, as well as the cogent criticisms of process-oriented diagnostic and remedial procedures, have induced a conceptual crisis in the field of learning disabilities. Are we to continue to view deficits in basic psychological processes as the essence of a 
learning disability, or do we eschew the description of processing deficiencies in favor of careful descriptions of academic skills? Do we want to continue to maintain a separate identity for learning disabled children within the larger class of general underachievement?

Ideas about processing deficiencies have had a long and honored place in the development of knowledge about children with specific learning problems (Hallahan \& Cruickshank 1973). After all, when a child of normal general intelligence receives essentially the same classroom stimuli and instructional programs as other children and yet makes a very different response, it is logical to assume that the child is doing something differently with the presented information. In the absence of a gross behavioral disturbance or an obvious lack of attention or effort, whatever is deficient about the learning disabled child likely involves less obvious behaviors that may or may not be directly observable. These deviant behaviors, particularly the ones taking place "inside the head" are those that have typically been referred to as the psychological processes underlying poor achievement.

Heinz Werner, one of the most important conceptual forebearers of process-oriented approaches to learning disabilities, strongly emphasized the necessity of understanding a child's poor achievement in terms of the psychological processes involved. Werner maintained (1937) that developmental psychology would profit in understanding, and pedagogy in effectiveness, if the attempt were made to understand "the manner in which the child thinks" rather than being content with simple measures of speed and accuracy. More recently, Estes (1974) has made a strong case for more research designed to develop understanding of the different cognitive processes required for performance on standard intellectual tasks. In his words, "In every type of intellectual task, any given level of performance can arise in many different ways" (p. 749). Thus understanding of the deficient reasoning or perceptual processes underlying a given response is essential in the development of remedial procedures that will be sensitive to the most important intellectual problems of the child.

Given a strong conceptual base for seeing a learning disability as the expression of deficiencies in one or more of the psychological processes required for learning, why has this approach experienced so much trouble in practice? The problems of applying process-oriented approaches stem primarily from inadequacies in the measurement and conceptualization of the particular processes with which diagnosticians have been concerned. Difficulties in measuring the psychological processes underlying intellectual functioning are not unique to the field of learning disabilities. Even researchers in developmental psychology, who devote full time to experimentation on specific areas of cognitive development, experience the problems involved in diagnosing intellectual skills as "many, varied, and very, very troublesome" (Flavell 1977, p. 20). Criticisms of process-oriented approaches to the study of learning disabilities generally have been well founded because those involved in applying the method have usually not been sensitive to many of the problems involved in diagnosing deficiencies in processing activities.

\section{WHAT IS A PSYCHOLOGICAL PROCESS?}

Before proceeding with a discussion of technical problems involved in the application of processoriented approaches, a clear definition of what is meant by a "psychological process" is needed. Although the term has been used in a variety of contexts, it has received its most complete development within the information-processing models of human cognition. The informationprocessing approach is of fairly recent origin (Massaro 1975) and was developed in the aftermath of successful simulation of human cognitive achievements (i.e., chess playing and numerical calculations) by computers. The availability of clear descriptions of the different processes by which computers solve human-like intellectual problems led researchers to hope that similar 
descriptions of internal psychological events intervening between receipt of a stimulus and emission of a response might also be developed for humans. Thus information-processing accounts treat mental processes in terms of different operations performed on information. These accounts generally conceive of human cognition as occurring in a series of discrete stages, with information operated on at one stage passed on as input to the next stage for further processing. Processes, then, are constituted of specific covert behaviors, which transform and manipulate information between the time it enters as a stimulus and the time a response to it is selected.

Perhaps an example will help to make the notion of psychological process more concrete. If you were asked to memorize a sequence of visually presented letters, how would you accomplish the task? Information-processing research has shown that the vast majority of adults and children recode the visual stimuli into their auditory equivalents and then rehearse (repeat over and over) these auditory codes. This account is justified by experimental evidence, which shows that strings of letters that have confusing auditory equivalents are more difficult to remember than those that are similar visually (Conrad 1964). In this case, both the recoding of stimuli from visual to auditory codes and rehearsal are conceived to be psychological processes necessary for efficient performance of this task. If an auditory code is not available or if the subject does not engage in rehearsal, the task becomes much more difficult and lower scores are obtained.

It is important to recognize that most processes are simply theoretical constructs developed to explain patterns of behavior on certain tasks. Although some processes such as rehearsal in young children (Flavell, Beach, \& Chinsky 1966) and various sorting and categorization activities (Moely, Olson, Halwes, \& Flavell 1969) may be directly observable, most psychological processes are inferred from experimental evidence. Because the constructs are inferential, those who study psychological processes must struggle repeatedly with validity issues in measurement (cf.
Smedslund 1969). Thus attempts to apply process-oriented approaches to the diagnosis and treatment of learning disabilities face some very difficult tasks in measurement that have not been adequately resolved at present.

\section{PROBLEMS IN THE MEASUREMENT OF PSYCHOLOGICAL PROCESSES}

To treat in detail the various problems associated with measurement of inferred processes is beyond the scope of this report. However, two different kinds of problems will be mentioned briefly, and the reader is referred to articles by Flavell (1977), Bortner and Birch (1970), and Baumeister (1967) for more thorough discussions of these and similar problems.

\section{Corroborating Evidence}

One of the most common mistakes that diagnosticians make is to assume that deficiency in a given psychological process is adequately demonstrated by poor performance on one kind of test. Although most practitioners are aware that they need corroborating evidence from several tests to be sure of their diagnosis, most of the "corroborating" tests are basically similar and do not vary in theoretically meaningful ways. Thus corroborating tests normally enhance the reliability of the measurement but may not contribute much to its validity. A case in point is provided by the Bender Motor Gestalt Test (Bender 1938), which is commonly assumed to measure perceptual-motor coordination. The diagnosis of perceptual-motor problems derived from a low score on the Bender test is often corroborated by using various subtests of the Frostig Developmental Test of Visual Perception (Frostig, Lefever, \& Wittlesey 1964). However, both of these instruments are paper-and-pencil tests and have many similar performance requirements. These similarities of administration are important in light of data (Fleishman 1967) indicating that one's score on a test of perceptualmotor processing skill depends strongly on how it 
is measured. An apparatus test frequently provides a different score than a paper-and pencil test. Thus diagnosticians cannot be certain whether a child's low scores on the Bender and Frostig tests are due to deficiencies in basic perceptual-motor processes or whether they actually depend most heavily on unknown factors associated with the particular method of measurement used.

To make an adequate assessment of psychological processes, one needs a well-developed theory of the test that specifies the processing activities required for its performance. Then if a child scores low on the test, follow-up tests that systematically eliminate alternative interpretative hypotheses may be used to pinpoint the processing problem that was most directly responsible for the poor performance. As Flavell (1977) has pointed out, "Every task demands from the child knowledge and skills other than, and in addition to, the target concept or ability it was designed to tap" (p. 224). Thus psychological processes cannot be reliably measured by a single operation.

For example, if a child does poorly on tests that require the immediate repetition of orally presented sequences of digit or words, the diagnosis may be "sequencing" or "short-term memory problems." However, we currently have no reliable way of discovering which of several processes may be responsible for this performance deficit. Again, what is needed are followup tests that vary the task's parameters in such a way that the basic processing problem will be identified. Psychological processes are most reliably measured when critical features of a task are manipulated; they are reflected in specific patterns of performance in response to these manipulations.

\section{Relationship between Test Results and Classroom Performance}

A second difficulty with process-oriented approaches is that it is often difficult to specify the nature of the relationship existing between the skills measured on diagnostic tests and perfor- mance in the classroom. For example, there is quite consistent evidence that children with specific reading problems perform poorly on tests of short-term sequential memory (Torgesen 1978). Yet no one seriously believes that children fail to learn to read because they cannot repeat sequences of digits. Rather, the assumption is made that the digit span task somehow taps underlying processes that are important both to performance on the task and to learning to read. This problem is related to that of corroborating evidence because, in the absence of a clear understanding of the processes responsible for poor performance on the tast, demonstration of how the diagnosis is actually relevant to the academic failure is difficult. The failure to adequately assess underlying processes also makes it impossible to derive directly from the test results a set of remedial procedures that have conceptual relevance to the academic problem.

\section{ASSUMPTIONSOFTHEPROCESS- ORIENTED APPROACH}

In addition to technical problems in measurement, the traditional process-oriented approach to diagnosis also suffers from serious deficiencies in several of its basic assumptions. Three of the most important tenets of processoriented techniques are as follows: (1) the basic psychological processes necessary for learning can be identified and measured; (2) these processing skills can be trained; and (3) training on a given skill within one task setting will generalize to other academic skills. Currently there are serious problems with at least two of these assumptions.

The first assumption is far too general. Research in cognitive development over the last 15 years points to specificity of functioning; individual differences in performance appear to depend heavily on specific aspects of the task, setting, instructions, and materials (Flavell 1977). Thus diagnostic and research efforts would probably be most fruitful if they sought to identify the processes that are responsible for 
failure on a specific task within a specific setting. When stated in these terms, there is clear evidence that such processes can be identified and measured (cf. Hagen \& Stanovitch 1977). There is also good evidence that such specifically defined subprocesses can be trained so that performance on a given task is dramatically improved. For example, Butterfield, Wambold, and Belmont (1973) have shown that the shortterm memory skills of retarded children can approach those of their nonretarded peers if the retardates are trained to use the same processing activities as normal children.

The final assumption, like the first, also has not received support in research on cognitive development. Even within a narrowly defined skill area such as memory where impressive training effects have been demonstrated, there is still little evidence for generalization of processing skills from one kind of task to another (Campione \& Brown 1977). Generalization has also been a problem in research that has tried to show that training in "basic psychological processes," as measured by such tests as the Illinois Test of Psycholinguistic Abilities (Kirk, McCarthy, \& Kirk 1968), can lead to improvement in academic skills (such as reading and mathematics). Although some of the abilities measured by these diagnostic tests can be trained, there is little solid evidence of generalization to important academic skills (Hallahan \& Cruickshank 1973).

\section{PROCESS ASSESSMENT VS. TASK ANALYSIS}

Process-oriented approaches to diagnosis and treatment of learning disabilities are essentially child centered. That is, they attempt to identify learning problems lying within the child. Another assessment model that is often seen as competing with process-oriented approaches is task analysis, in which the diagnostician attempts to break down complex tasks like reading into component subtasks so that an ordered series of skills can be identified. If a child experiences difficulty in reading, the diagnostician's task is to identify the prerequisite skills the child has not learned so that they may be taught to him. Task analysts make no inferences about processing problems within the child as a source of learning difficulty. Rather they typically assume that poor performance on tests of a prerequisite skill is the result of a failure to practice the skill (Smead 1977).

One of the major advantages of the taskanalysis approach is that it provides information that is directly relevant to instruction in academic skills. The teacher can provide extra instruction for specific skills on which the child is weak. However, from the point of view of traditional process-oriented approaches to learning disabilities, task analysis does not offer an adequate conceptualization of individual differences in cognitive functioning that can have an important impact both on what particular skills and in what manner a child is capable of learning. While taskanalysis approaches assume that failure to attain prerequisite skills (those necessary for more complex tasks like reading) is the result of lack of opportunity to practice them, process-oriented theorists recognize other sources of variance in these skills. As Bortner (1971) has pointed out, there is convincing evidence available that loss of function in specific skill areas (reading, language expression and reception, calculating ability) can result from various kinds of damage to the central nervous system. Children who perform poorly on an academic subtask because of organic factors may experience different processing problems than those who perform poorly because of lack of experience. These two groups of children may also require different kinds of educational treatment even though they are weak in similar skills.

\section{A NEW APPROACH TO PROCESS ASSESSMENT}

A possible solution to many of the problems of traditional process-oriented approaches lies in the integration of important concepts from this approach with task analysis. The difficulties with several of the basic assumptions of process- 
oriented diagnosis already reviewed suggest that the processes studied by traditional approaches have not been tied closely enough to specific academic tasks. Traditional approaches have attempted to analyze or "fractionate" (Mann \& Phillips 1967) the child rather than the task. Much of the previous work in this area has sought to identify general learning skills (perception, shortterm memory, expressive and receptive language) on which learning disabled children are different from their normally achieving peers. These approaches focus on the child's "equipment for learning" and refer only minimally to the specific tasks that must be learned. The approach advocated here is that indentification of the processes responsible for poor learning should start by an analysis of the task rather than the child.

At this point we must digress to ask an important question. How do the "component or prerequisite skills" measured by behaviorally oriented task analysts differ from the "psychological processes" measured by more traditional diagnosticians? Both are thought to be subskills that are necessary before more complex skills can be smoothly executed. The measurement of both requires tests that break down complex behaviors into simpler ones. Perhaps the most basic difference between component skills and psychological processes in that identification of the latter generally involves some form of inference, whereas the former is stated simply in terms of the actual deficient behaviors involved. In addition, psychological processes have typically been measured by tasks not typically taught in school, such as copying geometric forms or recalling sequences of digits. In the traditional processing approach, inferences and the concepts they generate have been necessary in the attempt to makelthe nonacademic measurement task relevant to learning problems in another domain. In fact, concepts of deficient underlying processes are what bridge the gap between diagnostic and remedial efforts in process-oriented approaches (Torgeson 1975). Inferences about processes also provide the basic underpinnings for the core concept in traditional approaches to learning disabili- ties - that these children learn poorly because of deficiencies in basic psychological processes.

Measurement of learning processes has typically used nonacademic tasks both because the processes were initially conceptualized within a child-centered frame of reference and because these nonacademic tasks were thought to provide a more pure or basic measure of the process in question. However, given the problems with specificity of functioning and generalization of training mentioned earlier, there are now compelling reasons to consider a task-centered approach to assessment. First of all, recent research has provided a solid data base from which to begin indentifying the component subskills involved in such complex tasks as reading and math. Much of this research has been done from an information-processing point of view so that component skills are frequently even identified as subprocesses (cf. LaBerge \& Samuels 1974, Perfetti \& Lesgold 1978). Although the measurement of processing activities by using simple materials not directly related to academic tasks may have seemed necessary in the past, as specificity in the measurement of academic subskills improves, it should approach a relatively pure assessment of basic processes. Thus identification of basic processing deficiencies underlying difficulties in reading, mathematics, and other academic content areas should become possible. The basic point of this argument is that if one had an adequate working knowledge of the component processes required for learning to read, one could do an adequate psychological examination on the basis of that knowledge. The diagnostic tests would involve assessment of the processing activities required to learn or to perform this specific skill.

There appear to be several advantages of a task-centered approach to the assessment of processing skills when compared with the strictly behavioral task analytic approach and to traditional process-oriented diagnostic strategies. It allows the retention of processing language to help differentiate learning disabled children from other kinds of underachievers. The continued use 
of inferences about processes operating within the child will also stimulate research designed to search for the antecedents of different kinds of processing deficiencies. It should also help to focus interest on efforts to determine which kinds of processing deficiencies can be affected by direct instruction and practice, and which kinds, because they result from structural impairment and cannot be trained, might require the restructuring of academic activities to avoid the area of deficiency. Behaviorally oriented task-analysis approaches support neither of these activities.

In contrast to child-centered process assessment, task-centered assessment would have more direct implications for educational practice. It should be similar to task-analysis approaches in providing a detailed breakdown of the specific competencies of the child with regard to the skills required for performance on an academic task. Because the child receives instruction and practice on skills that are directly required for performance in an important academic area, generalization of training is not a major concern. A move toward task-centered assessment may help to reduce the irrelevance of many psychological reports to activities taking place in the classroom.

\section{CONCLUSIONS}

The answer to the question in the title of this article is that we should keep the concept of psychological processes alive. The notion of deficiencies in the processing activities required for learning is essential to the maintenance of concern with learning disabled children as a special subgroup within the general population of underachievers. It also supports widely held views about learning disabled children's needs for special types of instruction not available in the regular classroom. Although the basic concept of processing deficiencies is important and viable, adjustments are needed in the manner in which these processes are conceptualized and measured. Diagnosticians and researchers need to be more sensitive to technical problems of assessment, particularly those involved in making inferences about processes that are not directly observable. Finally, diagnostic instruments that are taskoriented rather than child-centered should be developed. Such instruments could contribute substantially to our understanding of the specific processing problems of learning disabled children while simultaneously increasing the relevance of process assessment to education.

\section{ABOUT THE AUTHOR}

Joseph K. Torgeson obtained his $P h . D$. in psychology from the University of Michigan in 1976. He is currently an assistant professor in the school psychology program of the Department of Psychology at Florida State University. He is currently engaged in an active research program to study memory processes in learning disabled children. Requests for reprints should be addressed to him at Department of Psychology, Florida State University, Tallahassee, Fla. 32306.

\section{ACKNOWLEDGMENT}

Preparation of this manuscript was partially supported by a grant from the Thrasher Research Fund.

\section{REFERENCES}

Baumeister, A.A., Problems in comparative studies of mental retardates and normals. American Journal of Mental Deficiency, 1967, 71, 869-875.

Bender, L., A visual motor gestalt test and its clinical use. American Orthopsychiatric Association Research Monograph, 1938, No. 3.

Bortner, M., Phrenology, localization, and learning disabilities. Journal of Special Education, 1971, 5, 23-29.

Bortner, M., Birch, H.G., Cognitive capacity and cognitive competence. American Joumal of Mental Deficiency, 1970, 74, 735-744.

Butterfield, E.C., Wambold, C., Belmont, J.M., On the theory and practice of improving short-term memory. American Joumal of Mental Deficiency, 1973, 77, 654-669.

Campione, J.C., Brown, A.L., Memory and metamemory development in educable retarded children. In R.V. Kail, J.W. Hagen (Eds.), Perspectives on the Development of Memory and Cognition. Hillsdale, N.J.: Erlbaum Associates, 1977.

Conrad, R., Acoustic confusions in immediate memory. British Joumal of Psychology, 1964, 55, 75-84.

Estes, W.K., Learning theory and intelligence. American Psychologist, 1974, 29, 740-749.

Flavell, J.H., Cognitive Development. Englewood Cliffs, N.J.: Prentice-Hall, Inc., 1977.

Flavell, J.H., Beach, D.H., Chinsky, J.M., Spontaneous verbal rehearsal in a memory task as a function of age. Child Development, 1966, 37, 283-299.

Fleishman, E.A., Individual differences and motor learning. In R.M. Gagne, (Ed.), Learning and Individual Differences. Columbus, Ohio: Charles E. Merrill Books Inc., 1967. 
Frostig, M., Lefever, D.W., Whittlesey, J.R.B., The Marianne Frostig Developmental Test of Visual Perception. Palo Alto Calif. Consulting Psychology Press, 1964.

Hagen, J.W, Stanowitch, K.G., Memory: Strategies of Acquisition. R. V. Kail, J.W. Hagen (Eds.), Perspectives on the Development of Memory and Cognition. Hillsdale, N.J. Erlbaum Associates, 1977.

Hallahan, D.P., Cruickshank, W.M., Psycho-educational foundations of learning disabilites. Englewood Cliffs, N.J.: Prentice Hall, Inc., 1973.

Kirk, S.A., McCarthy, J.J., Kirk, W.D., Illinois Test of Psycholinguistic Abilities (revised ed.), Urbana, Ill.: University of Illinois Press, 1968.

La Berge, D., Samuels, S.J., Toward a theory of automatic information processing in reading. Cognitive Psychology, 1974, 6, 293-323.

Mann, L., Psychometric phrenology and the new faculty psychology: The case against ability assessment and training. Journal of Special Education, 1971, 5, 3-14.

Mann, L., Phillips, W.A., Factional practices in special education: a critique. Exceptional Children, 1967, 33, 311-317.

Massaro, D.W., Experimental Psychology and Information Processing. Chicago: Rand McNally \& Co., 1975.

Moely, B.E., Olson, F.A., Halwes, T.G., Flavel, J.H., Produc- tion deficiency in young children's clustered recall. Developmental Psychology, 1969, 1, 26-34.

Perfetti, C.A., Lesgold, A.M., Coding and comprehension in skilled reading and implications for reading instruction. In L.B. Resnick, P. Weaver (Eds.), Theory and Practice in Early Reading. Hillsdale, N.J.: Erlbaum Associates, 1978.

Senf, G.M., Implications of the final procedures for evaluating specific learning disabilities. Journal of Learning Disabilities, 1978, 11, 11-13.

Smead, V.S., Ability training and task analysis in diagnosticprescriptive teaching. Journal of Special Education, 1977, 11,114125 .

Smedslund, J., Psychological diagnostics. Psychological Bulletin, 1969, 71, 237-248.

Torgeson, J.K., Performance of reading disabled children on serial memory tests: A review. Reading Research Quarterly, 1978, 14, 57-87.

Torgeson, J.K., Problems and prospects in the study of learning disabilities. In E.M. Hetheringtron (Ed.), Review of Child Development Research Chicago: University of Chicago Press, 1975.

Werner, H., Process and achievement - a basic problem of education and developmental psychology. Harvard Educational Review, 1937, 7, 353-368. 